\title{
VERIFICATION OF THE POLISH GEODETIC REFERENCE FRAME BY MEANS OF A NEW SOLUTION BASED ON PERMANENT GNSS DATA FROM THE YEARS 2011-2014
}

\author{
T. Liwosz ${ }^{1}$, M. Ryczywolski² \\ ${ }^{1}$ Warsaw University of Technology \\ Faculty of Geodesy and Cartography \\ Department of Geodesy and Geodetic Astronomy \\ ${ }^{2}$ Head Office of Geodesy and Cartography
}

\begin{abstract}
The new solution for the Polish geodetic primary GNSS network was created to verify the currently used reference frame (PL-ETRF2000). The new solution is based on more GNSS data (more daily observation sessions included, a longer data timespan, GLONASS observations added) which were processed in a newer reference frame (IGb08) according to up-to-date methodology and using the latest version of Bernese GNSS Software. The new long-term soIution (spanning 3.7 years) was aligned to the IGb08 reference frame using a minimum constraints approach. We categorized Polish reference stations into two categories according to their data length. We obtained good agreement of the new solution with the PL-ETRF2000: for most stations position differences did not exceed $5 \mathrm{~mm}$ in horizontal, and $10 \mathrm{~mm}$ in vertical components. However, for 30 stations we observed discontinuities in position time series, mostly due to GNSS equipment changes, which occured after the introduction of PL-ETRF2000. Position changes due to the discontinuities reached $9.1 \mathrm{~mm}$ in horizontal components, and $26.9 \mathrm{~mm}$ in vertical components. The new soIution takes into account position discontinuities, and in addition also includes six new stations which were installed after the introduction of the PL-ETRF2000. Therefore, we propose to update the currently-used reference frame for the Polish geodetic primary network (PL-ETRF2000) with the new solution. The new solution was also accepted by the EUREF Technical Working Group as a class A solution (highest accuracy) according to EUREF standards.
\end{abstract}

Keywords: reference frames, GNSS, ETRF2000, ASG-EUPOS

\section{Introduction}

For over 20 years the national reference frame in Poland has been expressed in the European Terrestrial Reference System 89 (ETRS89). The first national GPS campaign whose solution 
was expressed in the ETRS89 was conducted in 1992 (Zielinski et al., 1994). This solution was accepted in 1994 by the EUREF Technical Working Group (TWG) as a class B standard for campaign solutions (1 $\mathrm{cm}$ accuracy at the epoch of observation). The solution included 11 Polish points and was further used as a reference for two densification GPS campaigns (conducted in 1994 and 1995) during which additional 348 passive ground points were established and measured (Jaworski and Swiatek, 2012). On the basis of these three campaigns the first GPS-based nation-wide reference frame for Poland, EUREF-89, was created.

In 2008, a network of about 100 permanent GNSS reference stations called ASG-EUPOS (Active Geodetic Network - European Position Determination System) was established by the Polish Head Office of Geodesy and Cartography (GUGiK). Nowadays, ASG-EUPOS is the primary national geodetic network in Poland and is maintained by GUGiK. The first official reference frame for ASG-EUPOS, named PL-ETRF2000, was adopted by GUGiK in 2013. The PL-ETRF2000 solution was created by the Warsaw University of Technology (Liwosz et al., 2011; Liwosz, 2012; Liwosz and Rogowski, 2012). The solution is based on GPS observations collected during two meausurement campaigns (66 days) conducted in 2008 and 2010/2011. We would like to point out that one of the main purposes of conducting these campaigns was to provide a link between the ASG-EUPOS network and EUREF-89, and the 66 days mentioned correspond to the days during which EUREF-89 passive ground points were observed. GPS observations from the two campaigns were processed within the IGS05 framework (based on ITRF2005) using Bernese GPS Software 5.0 (Dach et al., 2007). The final long-term solution was expressed in ETRF2000 at the epoch 2011.0 and adopted as PL-ETRF2000. The PL-ETRF2000 was presented to the EUREF TWG with a request for validation, but because it was computed in the old reference frame (ITRF2005) it was not accepted.

Because of the introduction of the new ITRF2008 (Altamimi et al., 2010) and the IGS08 (and its IGb08 update) framework (Rebischung et al., 2011) and due to the need for validaton of a Polish solution by the EUREF TWG, GUGiK have decided to prepare a new solution for the ASG-EUPOS network. Other reasons were that, since the introduction of the PLETRF2000, the equipment on 29 ASG-EUPOS stations has been changed (which may lead to coordinate changes), and 6 new stations have been installed which were not included in the PL-ETRF2000. This new long-term solution has been prepared by WUT and GUGiK. We have reprocessed continuous observations collected at ASG-EUPOS stations spanning 3.7 years (2012.3-2015.0) according to the latest developments in processing strategy for GNSS networks, using the latest version (5.2) of Bernese GNSS Software (Dach et al., 2015). In addition, we used GLONASS observations which were not included in previous analyses for the creation of PL-ETRF2000. We tested different variants for reference frame alignment of the long term solution to the IGb08 reference frame. In the new solution, we also divided ASG-EUPOS stations into two categories in terms of their data timespan and quality. The new solution was presented to the EUREF TWG as the "EUREF Poland 2015" campaign for its validation as an extension of ETRS89. The new solution was accepted by the TWG in Leipzig in 2015 as a class A solution (1 cm accuracy for positions and $1 \mathrm{~mm} /$ year for velocities at all epochs) according to EUREF standards (Bruyninx et al., 2013).

In this paper, we describe the new realization of ETRF2000 for the Polish national geodetic network, ASG-EUPOS, and we compare the new solution with the currently adopted geodetic reference frame in Poland (PL-ETRF2000). 


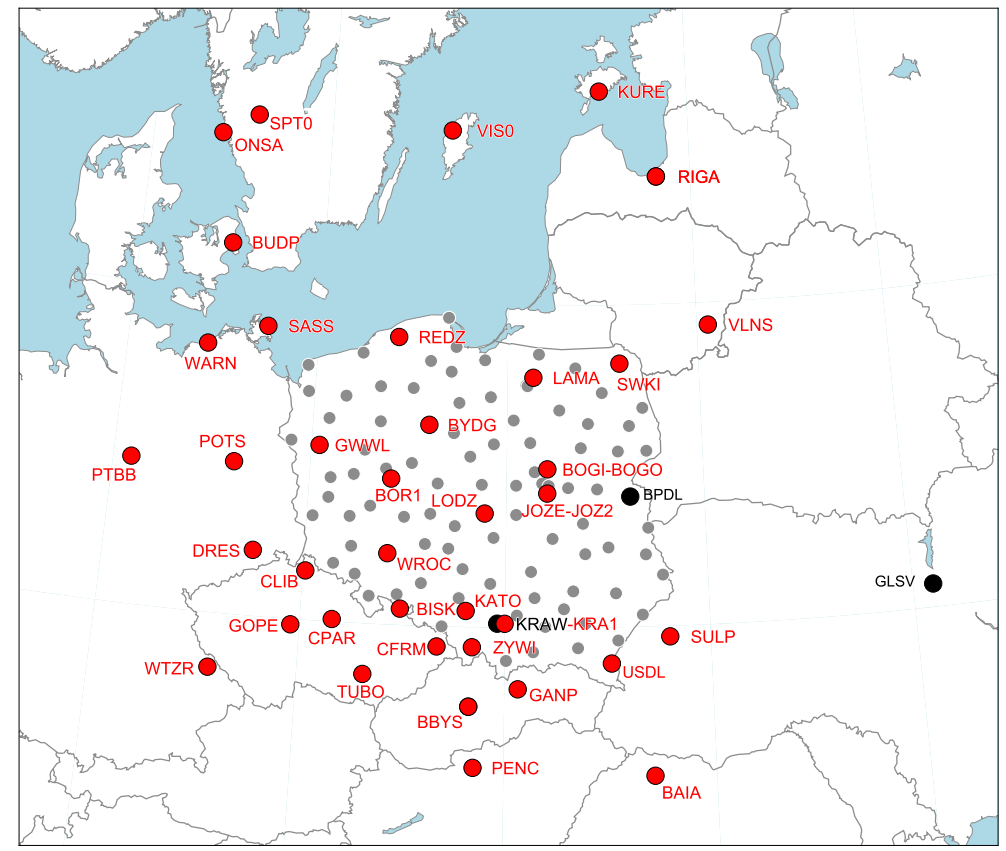

Fig. 1. Map of the campaign network with division for EPN sites used for frame definition (red dots), additional EPN sites (black dots) and densification sites (smaller gray dots)

\section{Campaign configuration}

The campaign network included 134 permanent GNSS reference stations (Figure 1). The network consisted of 91 Polish densification sites (Figure 2) and 43 EPN sites evenly distributed within and around the country of Poland (including Polish EPN sites).

From the list of 43 EPN stations, only 40 of them were regarded by EUREF as class $A$ stations (Kenyeres, 2010) in terms of their accuracy according to EPN guidelines (Bruyninx et al., 2013). These 40 EPN stations were used for the reference frame definition in our solutions (daily and long-term). Before selecting the EPN reference stations, the quality of their position time series (data gaps, scatter of residuals, significant seasonal signals) was inspected visually by means of plots from the EPN webpage (www.epncb.oma.be/ _productservices/timeseries/).

The remaining three EPN stations (BPDL, KRAW, and GLSV), categorized as class B, were included in the processing, but were not used for a reference frame definition. We included two Polish sites: BPDL and KRAW because they were part of the densification area. The classification of the third station (GLSV, Ukraine), was changed by EUREF from class A to $B$ after we started data processing, but for the sake of completeness we decided to retain GLSV in the next phases of GNSS data processing.

The campaign lasted for 3.7 years, between 17 April 2011 (GPS week 1632/0, DOY 107/2011) and 31 December 2014 (GPS week 1825/3, DOY 365/2014). This means in total 193.6 GPS weeks -1355 daily sessions. The observation sessions were considered to start at 00:00:00 and end at 23:59:30 (GPS time). All densification stations were observed permanently and almost all stations ( $92 \%$ of non-EPN sites) were observed during the whole period of the campaign. All densification sites are rooftop-type with a typical mounting based on an aluminium post attached to stable parts of the building. The equipment of densification sites was not homogeneous in terms of the satellite system; only $50 \%$ of stations were capable of tracking not only GPS, but also GLONASS satellites. Nevertheless, during 


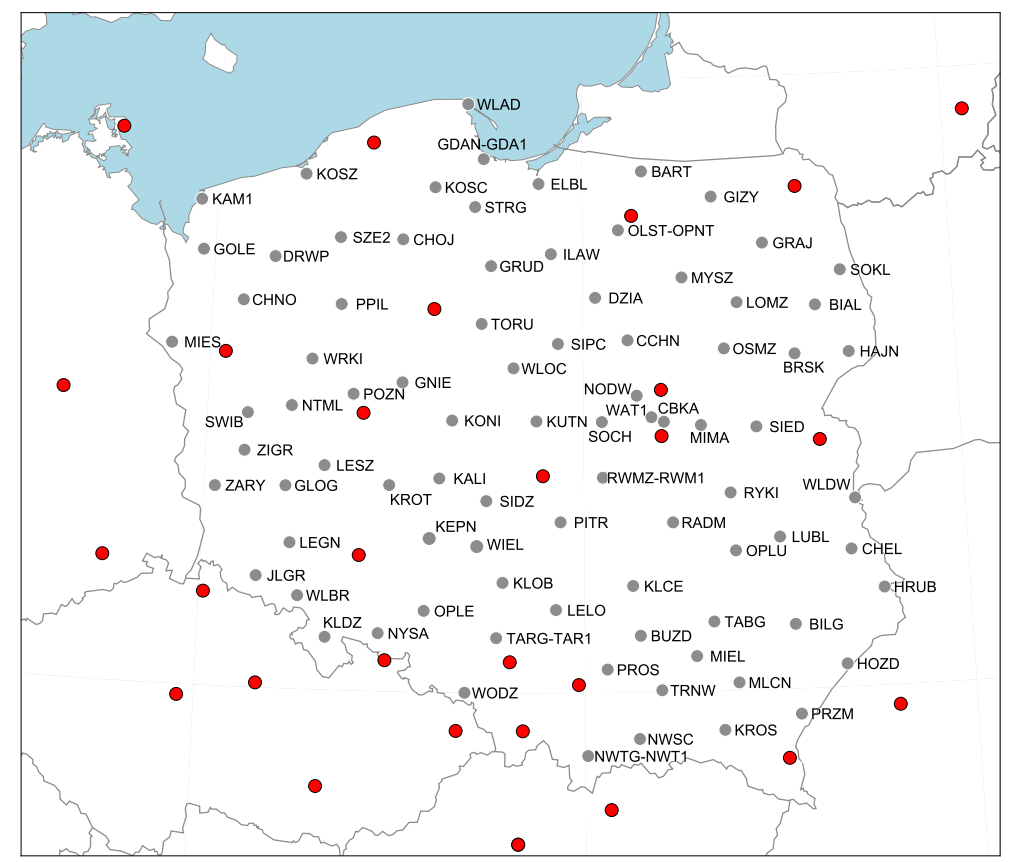

Fig. 2. Map of the ASG-EUPOS network

the GNSS data processing we also used GLONASS observations if they were available. Observations from other GNSS's were not considered.

\section{GNSS data processing}

GNSS observations collected at 134 GNSS stations were processed using Bernese GNSS Software version 5.2 (Dach et al., 2007). The processing was conducted according to the most recent guidelines for GNSS data analysis used by the EPN Local Analysis Centres (EPN LAC, 2013) and taking into account the guidelines for EUREF densification campaigns (Bruyninx et al., 2013).

During processing of GNSS observations, satellite orbits, satellite clocks and Earth rotation parameters were used from the International GNSS Service (IGS). Receiver clock corrections were computed using GPS code measurements. Then single differences were created between pairs of stations yielding an independent set of baselines for each daily session. Baselines were created using an algorithm which maximizes the number of common single difference observations over all baselines in the network, and the creation of baselines up to $200 \mathrm{~km}$ was prefered. Observations of each baseline were screened using triple differences for data cleaning, searched for carrier-phase cycle slips, and new ambiguities were set up. The ambiguities were resolved for GPS and GLONASS observations on a baseline-by-baseline basis. Three strategies, depending on baseline length, were used:

- direct ambiguity resolution on $L_{1}$ and $L_{2}$ using the SIGMA method for baselines shorter than $20 \mathrm{~km}$

- a two-step $L_{5} / L_{3}$ approach was used utilizing the SIGMA method for baseline lengths between 20 and $200 \mathrm{~km}$. Unresolved ambiguities were also attempted to be resolved using the QIF method

- a two-step $L_{6} / L_{3}$ approach was used utilizing the SIGMA method ( $L_{6}$ denotes MelbourneWübbena code and phase linear combination) for baseline lengths between 200 and $2000 \mathrm{~km}$. Unresolved ambiguities were also attempted to be resolved using the QIF method. 


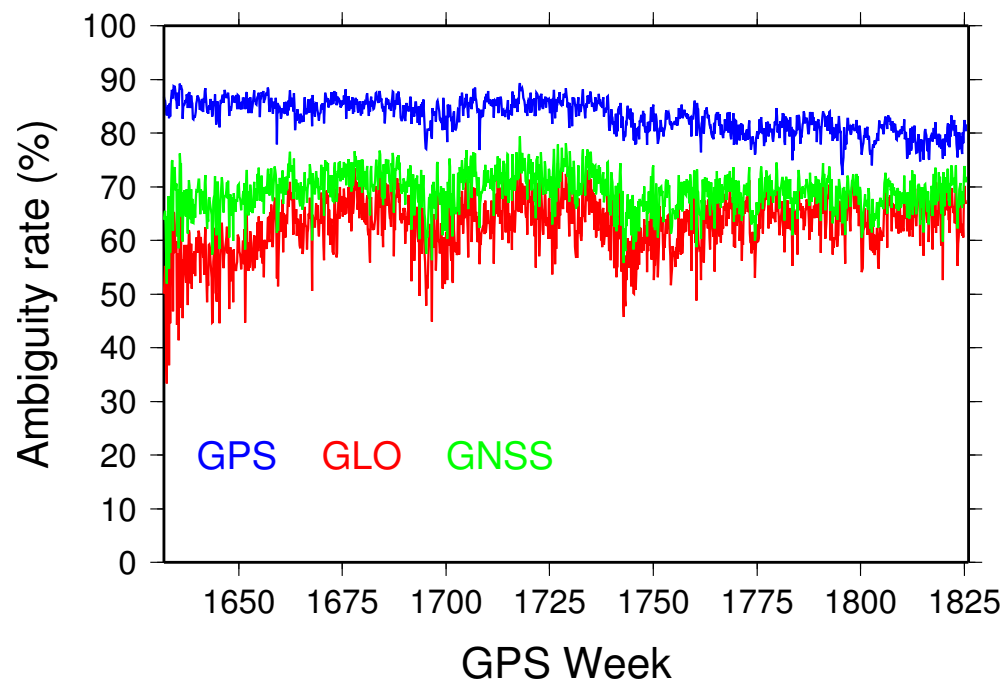

Fig. 3. Ambiguity resolution rate in daily sessions for GPS and GLONASS satellites

On average, it was possible to resolve $83 \%$ of GPS ambiguities, and $63 \%$ of GLONASS ambiguities. The mean ambiguity resolution rate in daily sessions for GPS and GLONASS satellites is presented in Figure 2.

After resolving the ambiguities separately for each baseline, a network solution was computed; the previously resolved ambiguities were introduced to the observation system. In the network solution tropospheric parameters, i.e., zenith delays and horizontal gradients, were also estimated. Zenith tropospheric delays were estimated at one-hour intervals for each station, while horizontal gradients were estimated at 24-hour intervals. As a result of performing the network solutions, daily normal equations were created which were further used for computing the final long-term solution. The daily solutions were aligned to the EUREF cumulative solution by applying no-net-translation minimum constraint conditions to the coordinates (extrapolated to the mean epoch of a session) of 40 EPN reference stations. More details on processing strategy are given in Table 1.

Tab. 1. Summary description of processing strategy

\begin{tabular}{ll}
\hline GNSS Orbits and ERPS & IGS \\
GNSS observations & GPS, GLONASS \\
Elevation mask & $3^{\circ}$ \\
Ambiguity resolution strategies & $200<L^{a} \leqslant 2000 \mathrm{~km}:$ L6/L3+QIF \\
& $20<L \leqslant 200 \mathrm{~km}:$ L5/L3+QIF \\
& $L \leqslant 20 \mathrm{~km}$ : direct L1\&L2 \\
A priori troposphere model & Saastamoinen + GMF , dry part \\
Mapping function for corrections & GMF, wet part \\
Time resolution for ZTD & 1 hour \\
Interval for troposphere horizontal gradients & 24 hours \\
lonosphere model & CODE global \\
Higher order ionosphere corrections & applied \\
Antenna calibrations & igs_08.atx + individual (EPN, ASG) \\
Reference frame & IGb08 (EPN cumulative solution) \\
\hline
\end{tabular}

${ }^{a}$ baseline length

${ }^{b}$ Global Mapping Function 


\section{Long-term solution}

The long-term solution was obtained by stacking all the daily normal equations from the period 2011.3-2015.0 using the ADDNEQ2 program of Bernese GNSS Software. Because of the long data span of observations (3.7 years), in addition to station coordinates, velocities were also estimated.

The long-term solution was aligned to the IGb08 reference frame, represented by the EPN cumulative solution (Kenyeres , 2010), using the minimum constraints (MC) approach. We tested three different $\mathrm{MC}$ conditions applied to the resulting long-term solution and its rate: (1) only no-net translation (NNT) conditions were applied (solution P1), (2) NNT and no-net scale (NNS) conditions were applied (solution P2), and (3) NNT, NNS, and no-net rotation (NNR) conditions were applied (solution P3). The alignment to the IGb08 was done by means of the coordinates and velocities of 40 EPN class $A$ reference stations. The EPN cumulative solution used in this work included data up to and including GPS week 1815 (named C1815).

As a result of daily normal equations stacking, we obtained for each solution variant: station coordinates at the mean epoch of observations (2013.14), station velocities, and time series of position residuals between the daily solutions and the combined solution. In the next step, the station position time series were inspected for discontinuities and outliers. Discontinuities in GNSS position time series are common and may occur for various reasons, e.g., due to GNSS antenna changes. If uncorrected, the discontinuities may lead to incorrect estimates of station positions and velocities. In general, the discontinuities were detected visually by inspecting the station position time series plots. However, for EPN stations, we applied a priori the same discontinuities that were used for the creation of the C1815 EUREF cumulative solution. If necessary, additional discontinuities for EPN stations were introduced after GPS week 1815 (we used data up to and including GPS week 1825, and the period 1815-1825 was not taken into account in the $\mathrm{C} 1815$ solution). If a discontinuity was noticed in station position time series at some epoch, additional coordinates and velocities were estimated for the station after the discontinuity epoch. However, station velocities before and after the discontinuity were tightly constrained to the same value (with $\sigma=10^{-3} \mathrm{~mm} / \mathrm{y}$ ).

The time series of position residuals between each daily solution and the combined solution were also inspected for outliers. Position residuals were identified as outliers if they were larger than $10 \mathrm{~mm}$ in north or east components, or $20 \mathrm{~mm}$ in vertical components.

The quality of EPN reference stations was checked by inspecting residuals of Helmert transformation between the EPN cumulative solution and our solution variants at three epochs: at the beginning, in the middle, and at the end of used data. Due to these discontinuities, we used 52 solutions (i.e. coordinates and velocities) for 40 EPN reference stations for the reference frame definition in our solution variants. Stations (solutions) were accepted as a reference if coordinate differences at all epochs did not exceed $4 \mathrm{~mm}$ horizontally and $5 \mathrm{~mm}$ vertically. In all 3 variants (P1,P2, and P3) we accepted 49 solutions for the reference frame definition, while 3 solutions were rejected (solutions for BISK, CFRM, and CPAR). According to EUREF guidelines for densification campaigns (Bruyninx et al., 2013), up to $10 \mathrm{~mm}$ difference is allowed for accepting EPN stations as a reference; in our variants, the $10 \mathrm{~mm}$ threshold was exceeded in two cases (BISK and CFRM). Table 2 shows that slightly better agreement between estimated coordinates and the reference solution was obtained for the P1 solution (only NNT conditions applied). Table 2 also shows the transformation parameters between each solution variant and the combined solution at three epochs which should ideally be all zero. The maximum absolute differences between estimated velocities and the $\mathrm{C} 1815$ reference velocities did not exceed $0.8 \mathrm{~mm} / \mathrm{y}$ 
Tab. 2. RMSs of position residuals and transformation parameters between each solution variant ( $P 1$, $\mathrm{P} 2$, P3) and the EPN C1815 solution. All values refer to three epochs: beginning (B), middle, and end $(E)$ of used observations

\begin{tabular}{|c|c|c|c|c|c|c|c|c|c|c|c|}
\hline Solution & $\begin{array}{l}\mathrm{RM} \\
\mathrm{N}\end{array}$ & $\begin{array}{c}\text { /com } \\
\text { E }\end{array}$ & $\begin{array}{c}\text { nent } \\
U\end{array}$ & $\begin{array}{l}\text { RMS } \\
(\mathrm{mm})\end{array}$ & $\begin{array}{r}T_{X} \\
(\mathrm{~mm})\end{array}$ & $\begin{array}{r}T_{Y} \\
(\mathrm{~mm})\end{array}$ & $\begin{array}{r}T_{Z} \\
(\mathrm{~mm})\end{array}$ & $\begin{array}{r}D \\
\text { (ppb) }\end{array}$ & $\begin{array}{r}R_{X} \\
\text { (mas) }\end{array}$ & $\begin{array}{r}R_{Y} \\
\text { (mas) }\end{array}$ & $\begin{array}{r}R_{Z} \\
\text { (mas) }\end{array}$ \\
\hline P1 & 0.7 & 0.6 & 1.4 & 1.0 & 0.0 & 0.0 & 0.0 & - & - & - & - \\
\hline P1B & 0.8 & 0.7 & 1.9 & 1.3 & 0.0 & 0.0 & 0.0 & - & - & - & - \\
\hline P1E & 0.9 & 0.8 & 2.5 & 1.6 & 0.0 & 0.0 & 0.0 & - & - & - & - \\
\hline P2 & 0.8 & 0.6 & 1.5 & 1.0 & 0.0 & 0.0 & 0.0 & 0.00 & - & - & - \\
\hline P2B & 1.0 & 0.7 & 2.1 & 1.4 & 0.0 & 0.0 & 0.0 & 0.00 & - & - & - \\
\hline P2E & 1.0 & 0.8 & 2.5 & 1.6 & 0.0 & 0.0 & 0.0 & 0.01 & - & - & - \\
\hline P3 & 0.9 & 0.7 & 1.7 & 1.2 & 0.0 & 0.0 & 0.0 & 0.00 & 0.000 & 0.000 & 0.000 \\
\hline P3B & 1.0 & 0.8 & 2.1 & 1.5 & 0.0 & 0.0 & 0.0 & 0.00 & 0.000 & 0.000 & 0.000 \\
\hline P3E & 1.0 & 0.8 & 2.4 & 1.6 & 0.0 & 0.0 & 0.0 & 0.00 & 0.001 & 0.000 & 0.000 \\
\hline
\end{tabular}

for horizontal velocities, or $2.0 \mathrm{~mm} / \mathrm{y}$ for vertical velocities. The comparison of velocities shows good agreement with the EUREF cumulative solution, and differences for all stations were below the $3 \mathrm{~mm} / \mathrm{y}$ threshold for accepting stations as a reference according to EUREF guidelines (Bruyninx et al., 2013). RMS's of velocity differences between three solution variants and cumulative solutions for accepted reference stations agreed at the $0.1 \mathrm{~mm} / \mathrm{y}$ level (Table 3). Comparisons of the coordinates and velocities obtained in three variants (P1, P2, P3) with respect to the EPN cumulative solution, showed small differences. In the densification area, coordinates of solutions P2 and P3 agreed with coordinates of the P1 solution at the $0.1 \mathrm{~mm}$ level horizontally and at the $0.2 \mathrm{~mm}$ level vertically; velocities agreed at the $0.1 \mathrm{~mm} / \mathrm{y}$ level. Since we obtained slightly better agreement of coordinates with the EPN C1815 solution for the P1 variant (Table 2) and comparable agreement of velocities for all three variants (Table 3), we chose the P1 variant as the final solution. Repeatability for each station from the P1 variant is presented in Figure 4. Mean repeatability of positions over all stations are: $1.1 \mathrm{~mm}$ for the north component, $1.0 \mathrm{~mm}$ for the east component, and 3.2 $\mathrm{mm}$ for the vertical component. (For other variants repeatabilities for horizontal components were the same, and for the vertical component $3.3 \mathrm{~mm}$ was obtained for the P2 variant, and $3.1 \mathrm{~mm}$ for the P3 variant.)

The final P1 solution includes 81 Polish reference stations (102 solutions due to discontinuities) which were observed for at least 2.7 years, expressed at the mean epoch of the campaign $(t=2013.14)$, by means of their estimated velocities. The remaining 10

Tab. 3. Agreement of velocities between three solution variants and $\mathrm{C} 1815$ solution

\begin{tabular}{llcccccc}
\hline Solution & MC & \multicolumn{3}{c}{ Velocity RMS } & \multicolumn{3}{c}{ Min/Max Differences } \\
& conditions & $\begin{array}{c}\mathrm{N} \\
(\mathrm{mm} / \mathrm{y})\end{array}$ & $\begin{array}{c}\mathrm{E} \\
(\mathrm{mm} / \mathrm{y})\end{array}$ & $\begin{array}{c}\mathrm{U} \\
(\mathrm{mm} / \mathrm{y})\end{array}$ & $\begin{array}{c}\mathrm{N} \\
(\mathrm{mm} / \mathrm{y})\end{array}$ & $\begin{array}{c}\mathrm{E} \\
(\mathrm{mm} / \mathrm{y})\end{array}$ & $\begin{array}{c}\mathrm{U} \\
(\mathrm{mm} / \mathrm{y})\end{array}$ \\
\hline P1 & NNT & 0.2 & 0.2 & 0.9 & $-0.6 / 0.7$ & $-0.7 / 0.6$ & $-2.0 / 1.7$ \\
P2 & NNT+NNS & 0.2 & 0.2 & 1.0 & $-0.6 / 0.7$ & $-0.7 / 0.6$ & $-1.9 / 1.7$ \\
P3 & NNT+NNS+NNR & 0.3 & 0.2 & 0.8 & $-0.7 / 0.8$ & $-0.7 / 0.6$ & $-2.0 / 1.4$ \\
\hline
\end{tabular}




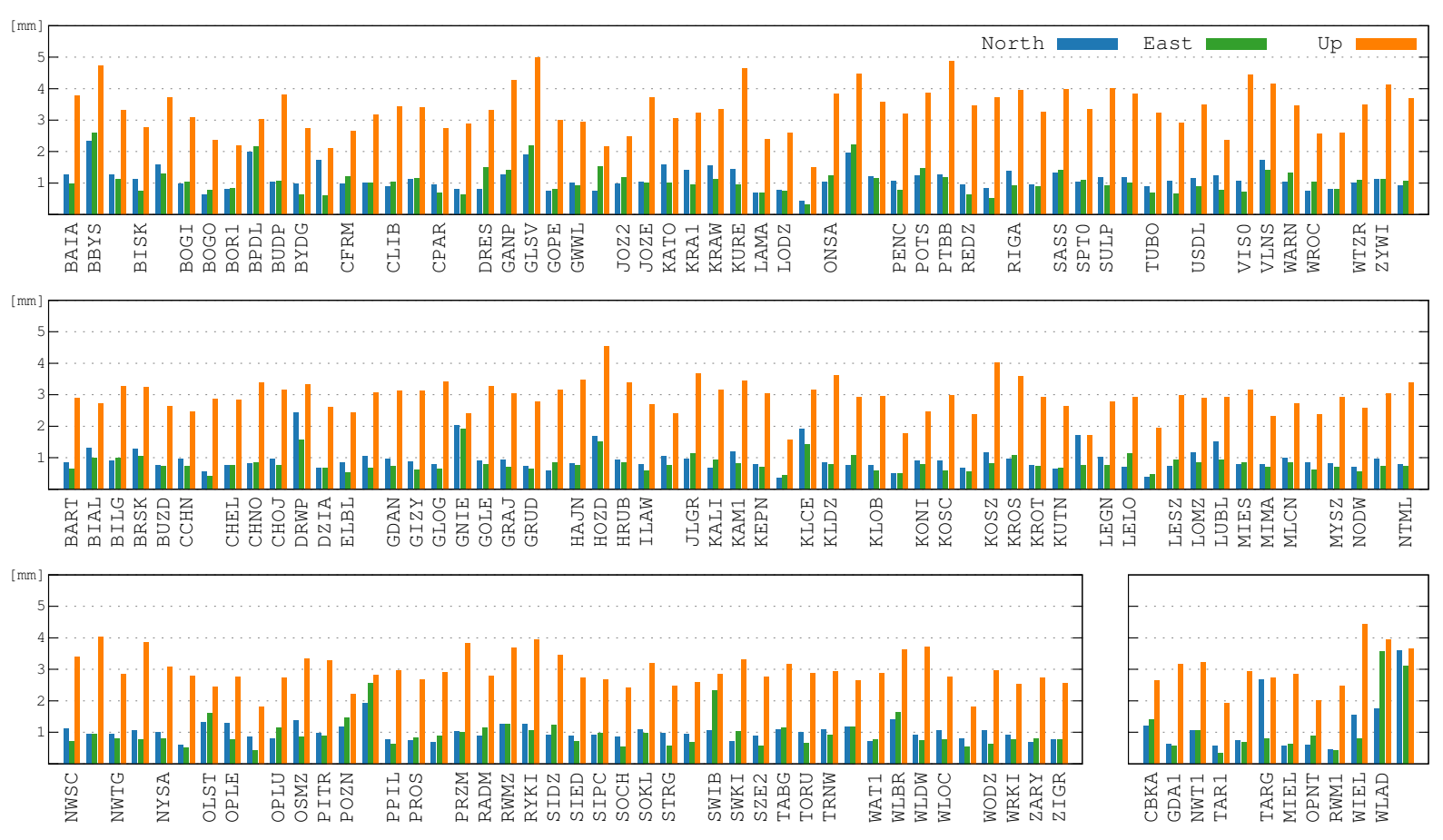

Fig. 4. Repeatability of station position time series of variant P1. For stations for which a discontinuity occured more than one repeatability values are shown. Top: repeatability for EPN sites, Middle and Bottom left: repeatability for densification sites, Bottom right: repeatability for shortly observing stations excluded from long-term solution

stations (with observations between 0.04 and 2.17 years), were excluded from the final long-term solution because their velocities may not have been reliable. Their coordinates were expressed at the epoch of the minimum position variance (EMPV) of each station (Altamimi et al., 2002). The repeatability for each of these 10 stations is presented in Figure 4 (bottom right).

In Table 4, we present mean position changes due to the discontinuities (expressed in the local frame of each station) for Polish EPN and densification sites obtained in the final P1 solution. The maximum (absolute) value for the north component is $-6.4 \mathrm{~mm}$ for station NODW, $7.5 \mathrm{~mm}$ for the east component for TRNW station, and $22.8 \mathrm{~mm}$ for the vertical component for BYDG EPN station. For the EPN sites the height changes are in the range of $-3.9 \mathrm{~mm}$ to 22.8 $\mathrm{mm}$. Significant height changes $(7.4-22.8 \mathrm{~mm})$ were observed for stations BYDG, GWWL, LODZ, REDZ, USDL, and ZYWI where Trimble NetR5 GNSS receivers and TRM55971.00_TZGD antennas were changed to Trimble NetR9 GNSS receivers and TRM59900.00_SCIS antennas. It should be noted that, both the previously installed antennas (TRM55971.00_TZGD) as well as new antennas (TRM59900.00_SCIS) were calibrated individually. In the case of WROC EPN station (height change: $-3.9 \mathrm{~mm}$ ) the Leica GRX1200GGPRO GNSS receiver and LEIAT504GG_LEIS antenna (type-mean calibration) was changed to a Leica GR25 GNSS receiver and a LEIAR25.R4_LEIT antenna (individual calibration). For densification ASG stations, both old and new receiver/antenna sets were not uniform. The equipment change for these stations involved changes of GPS-only to GNSS receivers (Trimble NetR5, Trimble NetR9, or Leica GR10) and in most cases type-mean calibrated antennas were replaced by individually-calibrated antennas. 
Tab. 4. List of discontinuities in position time series occurring in the densification campaign. Values of position changes expressed in local frame for north $(\triangle N)$, east $(\triangle E)$, and vertical $(\triangle \mathrm{U})$ components

\begin{tabular}{lllrrr}
\hline $\begin{array}{l}\text { Station } \\
\text { name }\end{array}$ & Date & Reason & $\begin{array}{r}\triangle \mathrm{N} \\
(\mathrm{mm})\end{array}$ & $\begin{array}{r}\triangle \mathrm{E} \\
(\mathrm{mm})\end{array}$ & $\begin{array}{r}\triangle \mathrm{U} \\
(\mathrm{mm})\end{array}$ \\
\hline \multicolumn{7}{c}{ EPN sites - discontinuities } \\
\hline BYDG & $09-09-2014$ & antenna change & -1.6 & 0.6 & 12.1 \\
GWWL & $28-10-2014$ & antenna change & 0.3 & 2.0 & 22.8 \\
LODZ & $30-10-2014$ & antenna change & 1.2 & 0.5 & 10.9 \\
REDZ & $29-10-2014$ & antenna change & 1.2 & -0.2 & 14.0 \\
USDL & $28-10-2014$ & antenna change & 2.8 & -0.6 & 14.6 \\
WROC & $22-10-2012$ & antenna change & 0.5 & -0.1 & -3.9 \\
ZYWI & $29-08-2014$ & antenna change & -0.9 & 0.5 & 7.4 \\
\hline ASG densification sites with long term solution & & \\
\hline CCHN & $10-09-2014$ & antenna change & -0.4 & -2.5 & -4.4 \\
ELBL & $06-07-2012$ & antenna change & 0.9 & -1.9 & -1.5 \\
GRUD & $04-11-2014$ & antenna change & -1.8 & -0.6 & -14.0 \\
ILAW & $07-11-2014$ & antenna change & 0.6 & 1.5 & -7.3 \\
KEPN & $03-11-2014$ & antenna change & -0.4 & 0.9 & 12.2 \\
KLDZ & $17-10-2014$ & antenna change & -2.1 & 1.4 & 9.4 \\
KLOB & $16-10-2014$ & antenna change & 0.1 & -0.7 & 6.9 \\
KOSC & $19-11-2014$ & antenna change & -4.3 & -0.2 & 7.4 \\
KUTN & $14-11-2014$ & antenna change & 1.0 & 0.5 & 6.7 \\
LELO & $24-10-2014$ & antenna change & 0.8 & -0.6 & 5.5 \\
MLCN & $24-10-2014$ & antenna change & -1.1 & 0.0 & 9.4 \\
NODW & $15-10-2013$ & unknown & -6.4 & -3.9 & -0.7 \\
NWSC & $17-11-2011$ & antenna change & -2.3 & -1.1 & -8.6 \\
NWTG & $18-11-2011$ & antenna change & 2.3 & 2.8 & 2.3 \\
NYSA & $23-09-2014$ & antenna change & -1.6 & -1.0 & 11.5 \\
OPLE & $24-09-2014$ & antenna change & 1.2 & -1.0 & 9.3 \\
POZN & $30-10-2013$ & antenna change & 2.6 & 4.1 & -3.9 \\
PROS & $22-11-2011$ & antenna change & 1.2 & 6.5 & 7.6 \\
STRG & $11-12-2013$ & antenna change & -0.9 & 0.8 & 7.8 \\
TRNW & $21-11-2011$ & antenna change & -5.9 & 7.5 & 8.7 \\
WLOC & $04-11-2014$ & antenna change & -1.3 & -0.9 & 12.0 \\
\hline ASG densification sites with EMPV solution & & \\
\hline TAR1 & $31-10-2014$ & antenna change & -2.6 & 5.0 & 10.6 \\
WLAD & $01-04-2014$ & antenna change & -4.7 & 2.7 & 14.0 \\
\hline
\end{tabular}




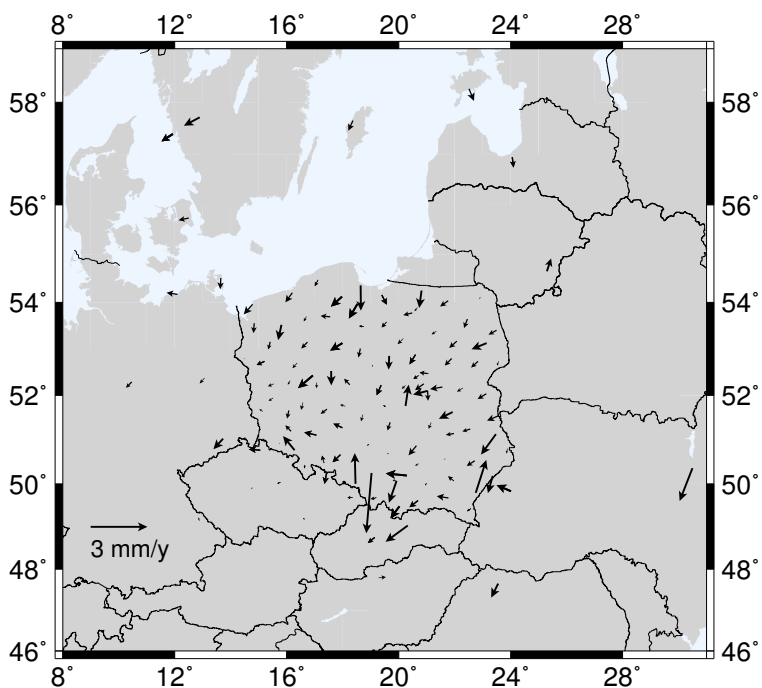

(a) P1 horizontal velocities

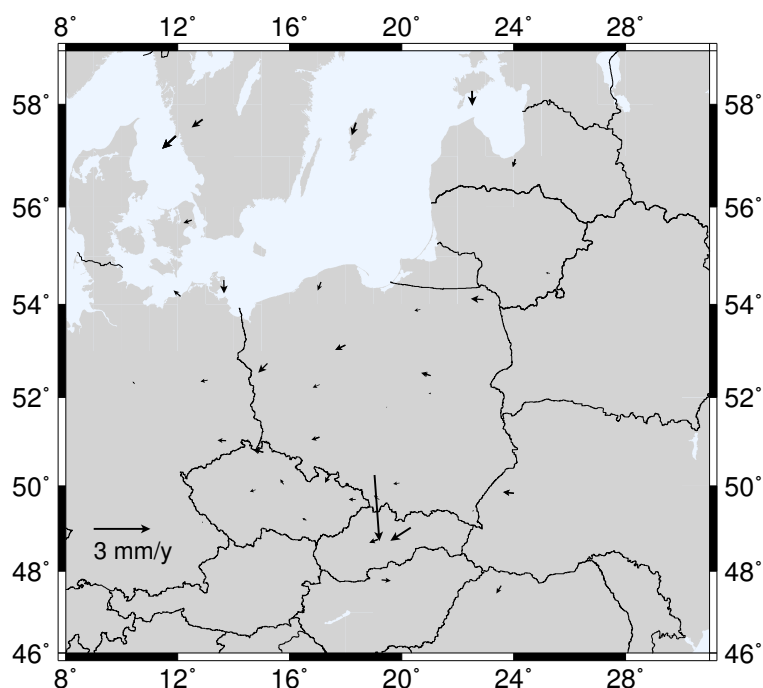

(c) C1815 horizontal velocities

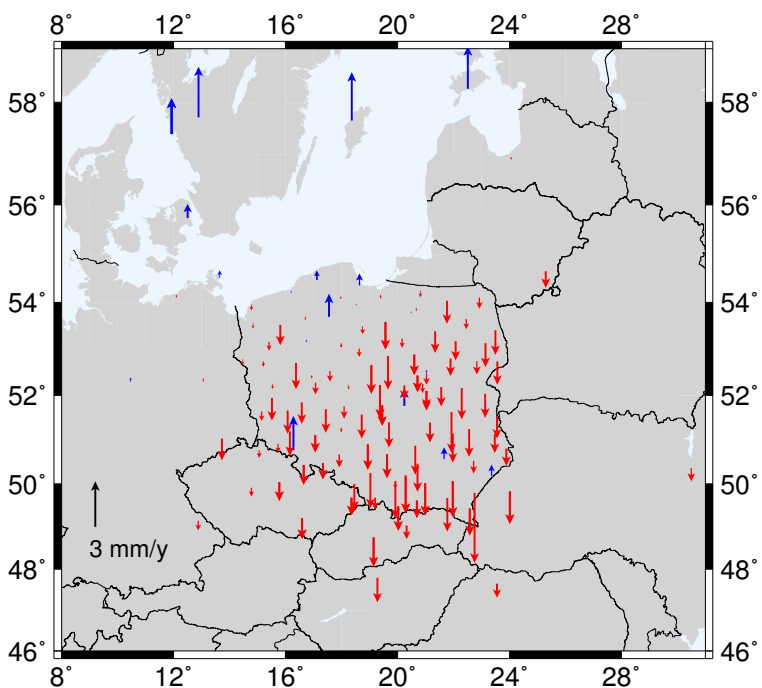

(b) P1 vertical velocities

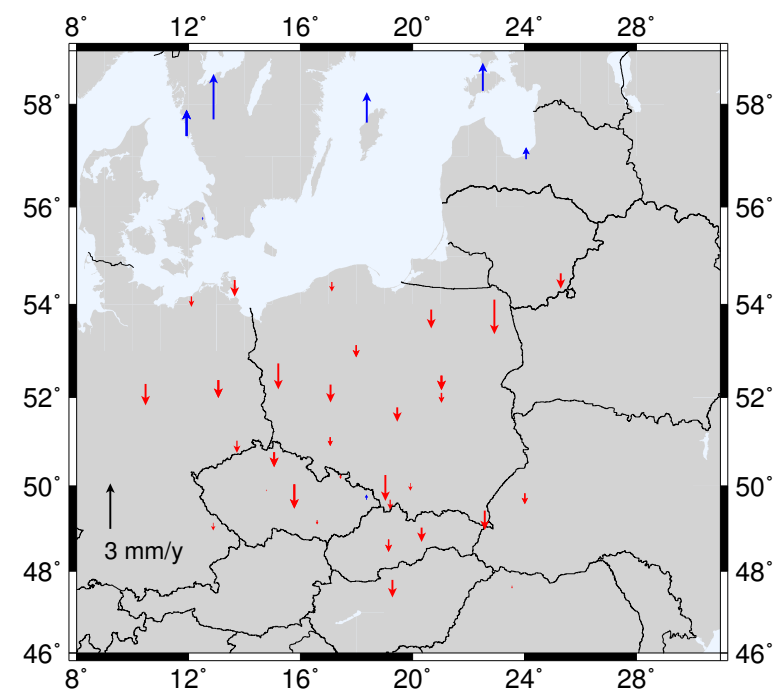

(d) C1815 vertical velocities

Fig. 5. ETRF2000 velocities of $\mathrm{P} 1$ solution and $\mathrm{C} 1815$ reference solution

The final long-term coordinates and velocities expressed in IGb08 from the P1 solution were transformed to the ETRF2000 using a 14-parameter transformation model (Boucher and Altamimi, 2011). For the 91 stations, for which velocities were estimated, transformation parameters were computed at the mean epoch of the campaign, i.e., 2013.14. For the 10 stations with short observation time span, transformation parameters were computed at the epoch of the minimum position variance of each station.

Horizontal and vertical velocities of solution P1 and EPN cumulative solution C1815 (for comparison) expressed in ETRF2000 are presented in Figure 5. Residuals of EPN reference stations for coordinates did not exceed $3.5 \mathrm{~mm}$ horizontally and $4 \mathrm{~mm}$ vertically. For velocities, residuals did not exceed $0.7 \mathrm{~mm} / \mathrm{y}$ horizontally and $2 \mathrm{~mm} / \mathrm{y}$ vertically (Figure 6 ).

\section{Comparison with Polish national reference frame - PL-ETRF2000}

The results from the current campaign were compared to the Polish national reference frame, called PL-ETRF2000. PL-ETRF2000 is based on GPS observations collected at ASG- 


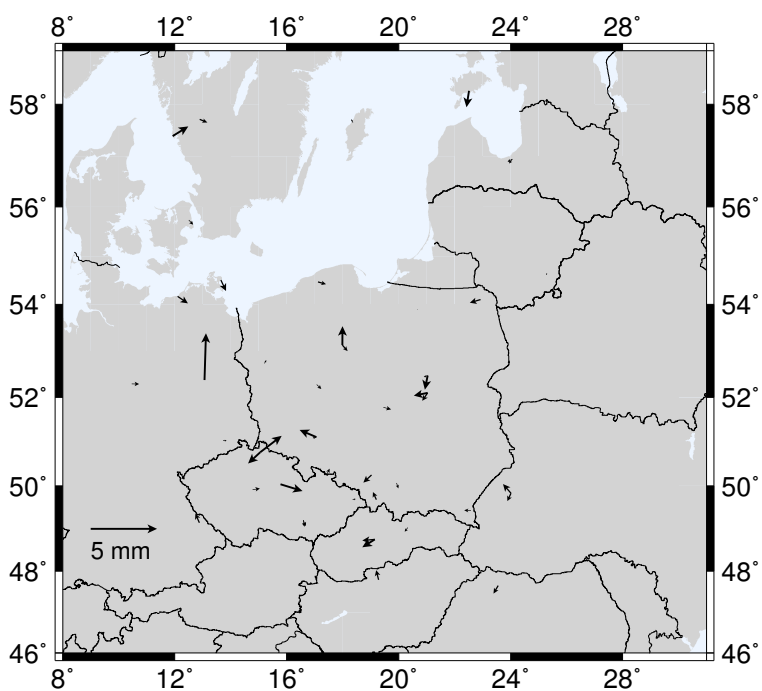

(a) horizontal coordinate differences

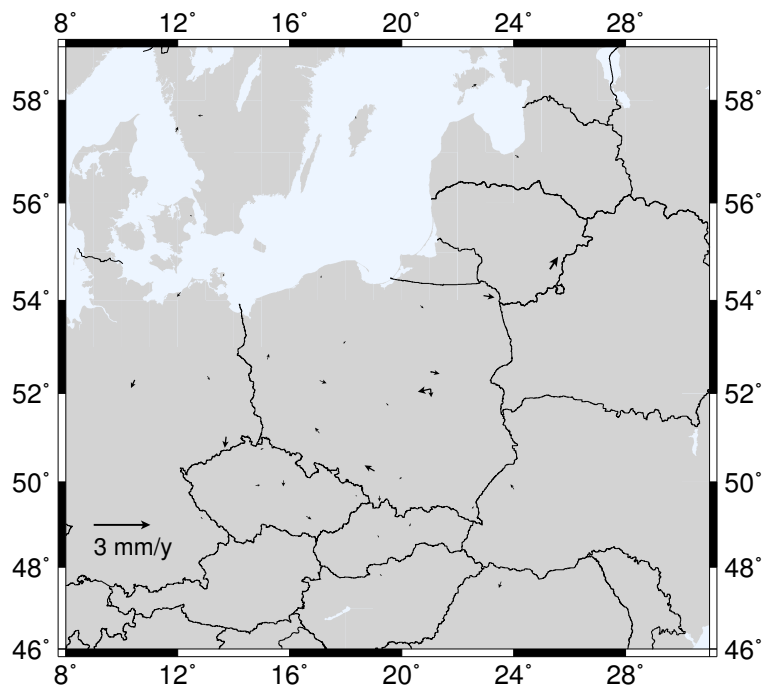

(c) horizontal velocity differences

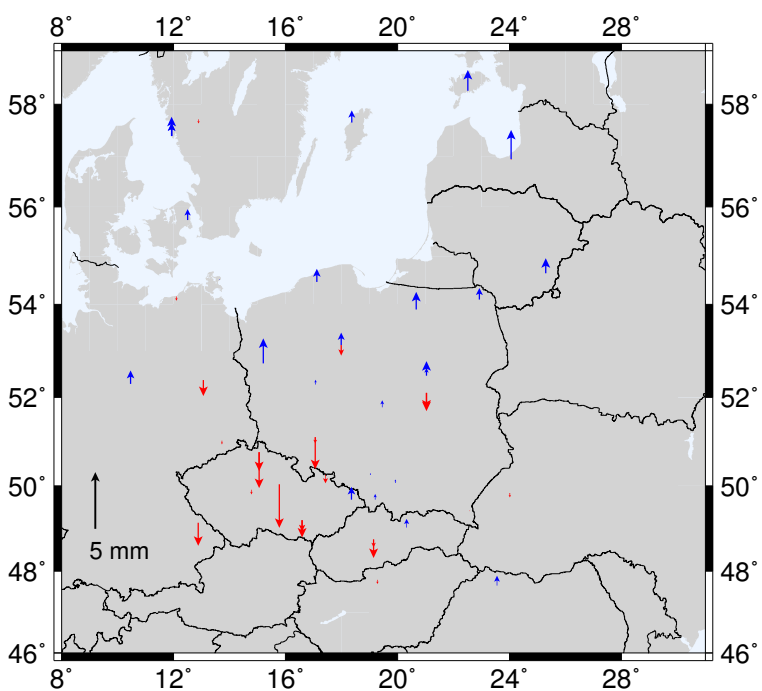

(b) vertical coordinate differences

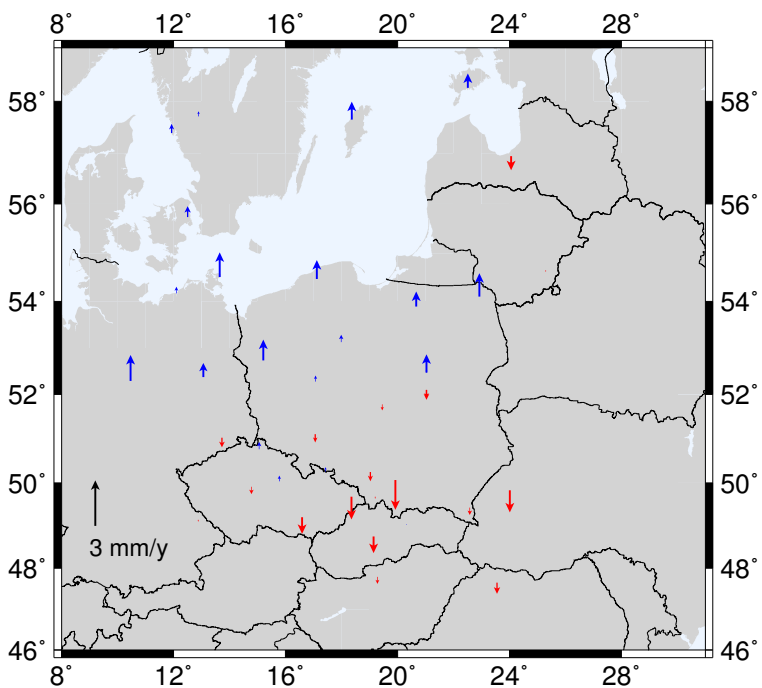

(d) vertical velocity differences

Fig. 6. Differences of ETRF2000 coordinates and velocities for accepted EPN reference stations between P1 solution and EPN C1815 cumulative solution

EUPOS stations during 66 days from the period 2008.3-2011.2 (2.9 years). The selected days correspond to two measurement campaigns conducted in 2008 and 2010/2011 during which EUREF-89 passive ground points were also observed. GPS observations from the two campaigns were processed in the IGS05 framework (reference frame, satellite orbits and antenna parameters) using Bernese GPS Software 5.0 (Dach et al., 2007). The longterm solution was aligned to the EUREF cumulative solution $\mathrm{C} 1600$, which was the EPN densification of the ITRF2005. The long term solution was expressed at the epoch of 2011.0 and transformed to the ETRF2000, which finally formed the PL-ETRF2000. The RMSs of position residuals of the long-term coordinates (at the mean campaign's epoch) with respect to the EUREF cumulative solution $(\mathrm{C} 1600)$ were: $0.8 \mathrm{~mm}$ for the north component, $0.7 \mathrm{~mm}$ for the east component, and $2.1 \mathrm{~mm}$ for the vertical component, and the RMS of transformation was $1.4 \mathrm{~mm}$. However, at the 2011.0 epoch the RMSs were slightly worse: $1.2 \mathrm{~mm}$ for north, 1.1 for east, $2.6 \mathrm{~mm}$ for vertical component. A slightly better alignment to 

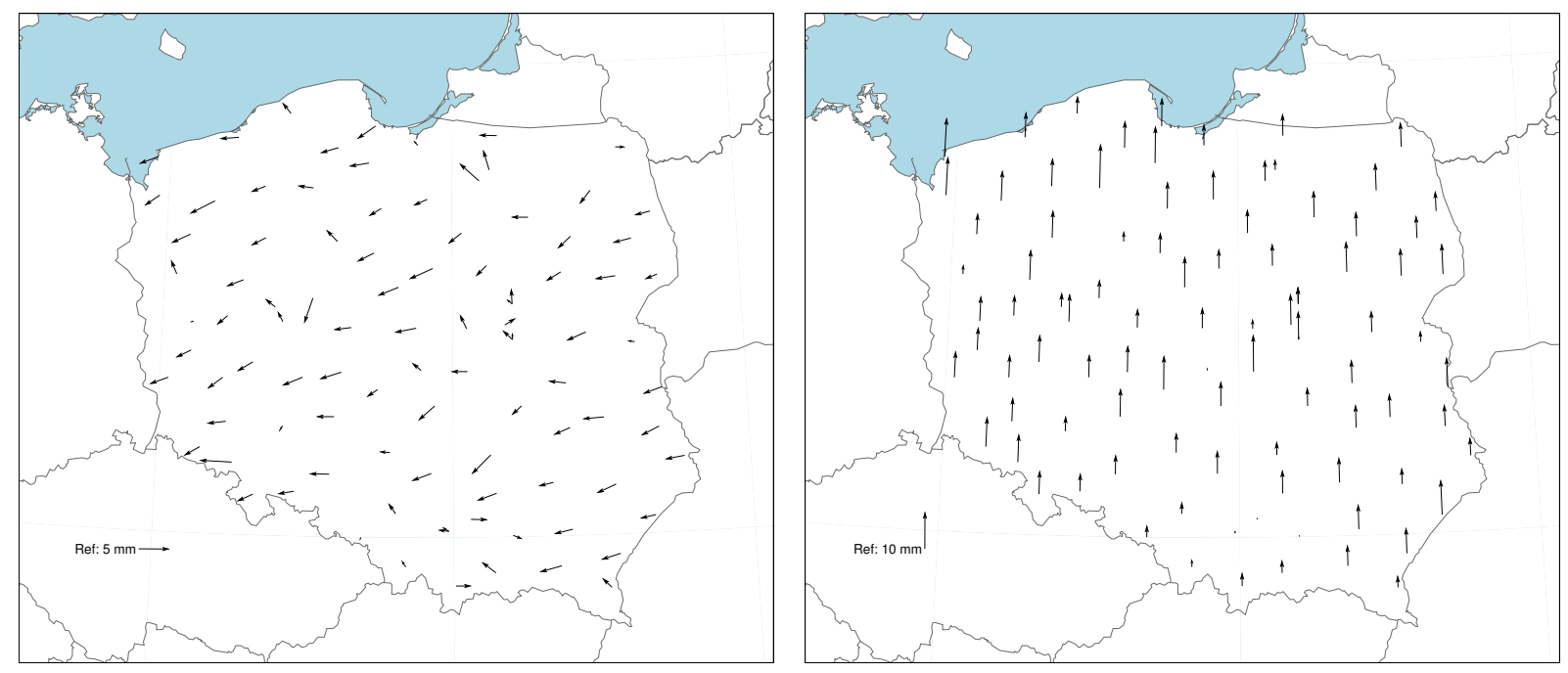

Fig. 7. Position differences between the new solution and the PL-ETRF2000 at epoch 2011.0. Left: horizontal differences. Right: vertical differences.

the EUREF cumulative solution was obtained for the new solution (values for $\mathrm{P} 1$ solution in Table 2). Differences in velocities cannot be compared reliably because in the old solution estimated velocities were constrained to the reference velocities of the cumulative solution.

The comparison of the two solutions was performed by using only stations working on the same equipment sets in both old and new campaigns. We perfomed two comparisons:

- The first one, presented on Fig. 7, is a direct comparison of positions of the new solution reduced to epoch 2011.0 by using estimated velocities, with the PL-ETRF2000

- The second one, presented on Fig. 8, is a comparison of positions of the new solution reduced to epoch 2011.0 and transformed into PL-ETRF2000 using a 7-parameter Helmert transformation, with the PL-ETRF2000

The comparisons presented show a good agreement of both solutions. Differences for datasets expressed at common epoch 2011.0, using newly estimated velocities (Figure 7), show a small but noticeable shift, which is mainly due to the difference between IGS05 and IGb08 reference frames. Differences after transformation (Figure 8) for a few sites show noticeable shifts in random directions. Nevertheless, presented differences are considered as negligible in terms of the stability of coordinates of the reference stations; the maximum position differences are at a level of $5 \mathrm{~mm}$ for the horizontal and $10 \mathrm{~mm}$ for the vertical component for both comparisons. Transformation parameters and short statistical summaries are presented in Table 5 and 6 respectively.

For the 27 sites for which the antenna changes occured, the differences between the old and new solutions may be greater (Table 7). For EPN sites, the height changes are in

Tab. 5. Transformation parameters between the new solution and the PL-ETRF2000 at epoch 2011.0. Transformation parameters were computed using 95 stations

\begin{tabular}{rcrrrrrrr}
\hline & $\mathrm{RMS}$ & $T_{1}$ & $T_{2}$ & $T_{3}$ & $\mathrm{D}$ & $R_{1}$ & $R_{2}$ & $\begin{array}{r}R_{3} \\
\mathrm{~mm} \\
\mathrm{~mm}\end{array}$ \\
$\mathrm{~mm}$ & $\mathrm{~mm}$ & $\mathrm{~mm}$ & $10^{-9}$ & mas & mas & mas \\
\hline uncertainty & 1.7 & -27.3 & -17.1 & 22.1 & 1.24 & 0.459 & -1.169 & -0.202 \\
& - & 6.9 & 6.2 & 6.0 & 0.08 & 0.187 & 0.247 & 0.181 \\
\hline
\end{tabular}



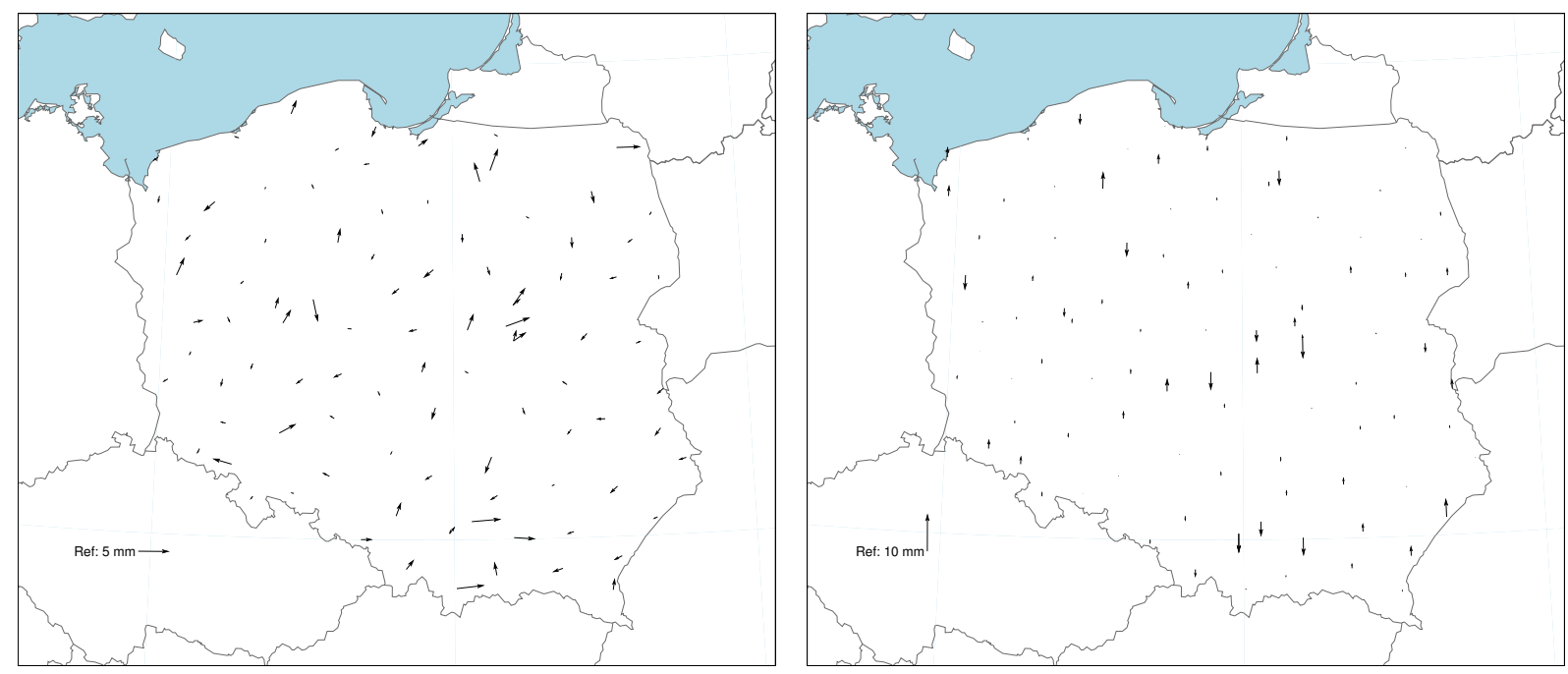

Fig. 8. Position differences at epoch 2011.0 between the new solution and the PL-ETRF2000 after 7-parameter Helmert transformation. Left: horizontal differences. Right: vertical differences

the range of $-2.5 \mathrm{~mm}$ to $26.9 \mathrm{~mm}$. For ASG densification sites, the level of height changes varies between -14 to $14 \mathrm{~mm}$. It should also be noted that significant position changes (several millimeters) occured for horizontal components as well (maximal change $-5.6 \mathrm{~mm}$ for TRNW). For station NODW, for which the reason of the discontinuity is unknown (Table 4), the north component changed by $-9.1 \mathrm{~mm}$.

\section{Conclusions}

The new solution for the ASG-EUPOS network was created by WUT and GUGiK to verify the currently-used reference frame (PL-ETRF2000) for the Polish national geodetic primary network. The new solution (1) is based on more GNSS data (more daily observation sessions included, GLONASS observations included, a longer data timespan), (2) was computed in a newer IGS framework (IGb08) using the latest version of Bernese GNSS software, and an up-to-date processing strategy, (3) takes into account the discontinuities in station positions which occured after the introduction of the currently-adopted reference frame, and (4) includes 6 new ASG-EUPOS stations, which were installed between 2011.5-2015.0, and therefore were not included in PL-ETRF2000.

The new solution showed good agreement with the currently-adopted reference frame (PL-ETR2000). For most stations the coordinate differences did not exceed $5 \mathrm{~mm}$ for the horizontal and $10 \mathrm{~mm}$ for the vertical component. However, for the 30 ASG-EUPOS stations,

Tab. 6. Statistical summary of the position differences between the new solution and the PLETRF2000. The new solution was reduced to common epoch 2011.0 using estimated velocities

\begin{tabular}{lrrrrrr}
\hline & \multicolumn{3}{c}{ no transformation } & \multicolumn{3}{c}{ with transformation } \\
& $\triangle \mathrm{N}$ & $\triangle \mathrm{E}$ & $\triangle \mathrm{U}$ & $\triangle \mathrm{N}$ & $\triangle \mathrm{E}$ & $\triangle \mathrm{U}$ \\
& $(\mathrm{mm})$ & $(\mathrm{mm})$ & $(\mathrm{mm})$ & $(\mathrm{mm})$ & $(\mathrm{mm})$ & $(\mathrm{mm})$ \\
\hline RMS & 1.4 & 2.5 & 6.4 & 1.3 & 1.4 & 2.2 \\
MEAN & -0.4 & -2.1 & 5.9 & 0.0 & 0.0 & 0.0 \\
MIN & -4.1 & -5.2 & -0.7 & -3.6 & -3.1 & -5.3 \\
MAX & 3.2 & 2.7 & 11.8 & 3.5 & 4.7 & 5.0 \\
\hline
\end{tabular}


Tab. 7. Discontinuities in station positions expressed in the PL-ETRF2000 reference frame

\begin{tabular}{|c|c|c|c|c|c|c|c|c|c|}
\hline $\begin{array}{c}\text { Site } \\
\text { name }\end{array}$ & $\begin{array}{r}\triangle \mathrm{N} \\
(\mathrm{mm})\end{array}$ & $\begin{array}{r}\Delta \mathrm{E} \\
(\mathrm{mm})\end{array}$ & $\underset{(\mathrm{mm})}{\triangle \mathrm{U}}$ & Network & $\begin{array}{c}\text { Site } \\
\text { name }\end{array}$ & $\begin{array}{r}\triangle \mathrm{N} \\
(\mathrm{mm})\end{array}$ & $\begin{array}{r}\triangle \mathrm{E} \\
(\mathrm{mm})\end{array}$ & $\begin{array}{r}\triangle \mathrm{U} \\
(\mathrm{mm})\end{array}$ & Network \\
\hline BYDG & -3.9 & 0.2 & 16.0 & EPN & KOSC & -3.9 & 0.4 & 7.5 & ASG \\
\hline GWWL & -2.5 & 0.7 & 26.9 & EPN & KUTN & 1.3 & 1.7 & 7.1 & ASG \\
\hline LODZ & -0.5 & -0.3 & 15.9 & EPN & LELO & 1.6 & 0.4 & 4.4 & ASG \\
\hline REDZ & -1.1 & -1.0 & 16.8 & EPN & MLCN & -0.8 & 0.9 & 7.2 & ASG \\
\hline USDL & 0.8 & -1.2 & 15.4 & EPN & NODW & -9.1 & -5.3 & -7.5 & ASG \\
\hline WROC & -1.0 & -2.9 & -2.5 & EPN & NWSC & -4.6 & -1.0 & -7.8 & ASG \\
\hline ZYWI & -2.5 & -1.0 & 9.8 & EPN & NWTG & 1.9 & -1.9 & 2.9 & ASG \\
\hline CCHN & 0.9 & -3.0 & -3.9 & ASG & NYSA & -1.7 & -0.6 & 11.7 & ASG \\
\hline ELBL & -0.2 & -3.5 & 0.0 & ASG & OPLE & 0.6 & 0.0 & 9.2 & ASG \\
\hline GRUD & -1.0 & -0.8 & -14.3 & ASG & POZN & 0.8 & 3.5 & -1.5 & ASG \\
\hline ILAW & 1.2 & 1.5 & -8.2 & ASG & PROS & 0.8 & 1.5 & 11.8 & ASG \\
\hline KEPN & -0.9 & 1.5 & 10.2 & ASG & STRG & -0.8 & 1.7 & 5.1 & ASG \\
\hline KLDZ & -1.4 & 1.6 & 8.2 & ASG & TRNW & -5.6 & 3.8 & 13.8 & ASG \\
\hline KLOB & -0.5 & -1.2 & 6.8 & ASG & WLOC & -0.4 & 0.2 & 10.1 & ASG \\
\hline
\end{tabular}

some discontinuities in positions were observed, which occured after the introduction of PLETRF2000. They were mostly caused (with one exception) by GNSS antenna replacements. Significant height differences (10 to $26.9 \mathrm{~mm}$ ) were observed even for stations at which individually-calibrated antennas were replaced by individually-calibrated antennas as well.

We propose to update the existing reference frame (PL-ETRF2000) for the Polish geodetic primary network with the new solution described in this paper. The update of PL-ETRF2000 is especially necessary for stations at which GNSS equipment was changed, and for new stations which were not included in the currently-adopted solution. Because the new solution is based on more GNSS data which were processed in the newer reference frame and according to the latest standards, it can also be regarded as a more accurate and consistent solution than the PL-ETRF2000 (e.g., better agreement with EUREF cumulative solution was obtained). It should be noted that the new solution was presented to the EUREF Technical Working Group as the Polish 2015 EUREF densification campaign and was accepted as a class A solution according to EUREF standards (Resolution No. 2 of the EUREF Symposium 2015 held in Lipsk, Germany).

\section{Acknowledgements}

The authors wish to thank the EUREF TWG members for their valuable remarks and suggestions concerning the creation of the "EUREF Poland 2015" campaign solution. The authors also thank two anonymous reviewers for their valuable comments which have improved the content of this paper.

\section{References}

Altamimi, Z., P. Sillard, C. Boucher (2002), ITRF2000: A New Release of the International Terrestrial Reference Frame for Earth Science Applications, J. Geophys. Res., 107(B10), 2214.

Altamimi, Z., Collilieux, X., Métivier, L. (2011), ITRF2008: an improved solution of the international terrestrial reference frame. J Geod (2011) 85: 457. doi:10.1007/s00190011-0444-4 
Boucher, C., Z. Altamimi (2011), Memo: Specifications for reference frame fixing in the analysis of a EUREF GPS campaign, http: //etrs89. ensg. ign.fr.

Bruyninx, C., Z. Altamimi, A. Caporali, A. Kenyeres, M. Lidberg, G. Stangl, J.A. Torres (2013), Guidelines for EUREF Densifications, Version 5, http: //www . epncb. oma . be.

Dach, R., S. Hugentobler, P. Fridez, M. Meindl (eds.) (2007) Bernese GPS Software Version 5.0. Astronomical Institute, University of Berne.

Dach, R., S. Lutz, P. Walser, P. Fridez (eds.) (2015) Bernese GNSS Software Version 5.2. Astronomical Institute, University of Berne.

EPN LAC (2013), Guidelines for the EPN Local Analysis Centres, http://www .epncb.oma .be/_documentation/guidelines/guidelines_analysis_centres.pdf.

Jaworski, L., A. Swiatek (2012) Comparison of coordinates of POLREF - the first order Polish national network - obtained from campaigns in 1994/95 and 2008/2010, Artificial Satellites, Vol. 47, No. 3 - 2012 DOI:10.2478/v10018-012-0017-7.

Kenyeres, A. (2010) Categorization of permanent GNSS reference stations, http: //www .epncb.oma.be/_productservices/coordinates/kenyeres_2010.pdf.

Liwosz, T., J. Rogowski, M. Kruczyk, M. Rajner, and W. Kurka (2011) Control adjustment of GNSS observations collected at ASG-EUPOS, EUREF-POL, EUVN, POLREF, and 1 st order points and assesment of the results (in Polish). Technical Raport for GUGiK (269 pp).

Liwosz, T. (2012) Control adjustment of GNSS observations collected at points belonging to: ASG-EUPOS, EUREF-POL, EUVN, POLREF, and 1st order networks (in Polish). Presentation at the seminar ,Integration of ASG-EUPOS with Polish geodetic primary network", GUGiK, May 21 2012, Warsaw

(http: //www .asgeupos.pl/webpg/graph/img/_news/00143/T2_21_05_2012.pdf)

Liwosz, T., J. Rogowski J. (2012) A new adjustment of Poland's national GNSS reference network, Symposium EUREF 2012, Saint Mandé, France 6 - 8 June 2012.

Rebischung, P., Griffiths, J., Ray, J., Schmid, R., Collilieux, X., Garayt, B. (2012) IGS08: the IGS realization of ITRF2008 GPS Solut, 16:483. DOI:10.1007/s10291-011-0248-2.

Zielinski, J.B., L. Jaworski, R. Zdunek, H. Seeger, G. Engelhardt, F. Toppe, J. Luthard (1994) Final Report about the EUREF-POL 1992 Campaign, EUREF 1994 Proceedeings.

\footnotetext{
Authors: Tomasz Liwosz ${ }^{1}$ (email: t.liwosz@gik.pw.edu.pl)

Marcin Ryczywolski (email: marcin.ryczywolski@gugik.gov.pl)

${ }^{1}$ Warsaw University of Technology

Faculty of Geodesy and Cartography

Department of Geodesy and Geodetic Astronomy

PI. Politechniki 1

00-661 Warsaw, Poland

${ }^{2}$ Head Office of Geodesy and Cartography

ul. Wspólna 2

00-926 Warsaw, Poland
} 